\title{
Corrigendum: Optically initialized robust valley-polarized holes in monolayer $\mathrm{WSe}_{2}$
}

Wei-Ting Hsu, Yen-Lun Chen, Chang-Hsiao Chen, Pang-Shiuan Liu, Tuo-Hung Hou, Lain-Jong Li \& Wen-Hao Chang

Nature Communications 6:8963 doi: 10.1038/ncomms9963 (2015); Published 25 Nov 2015; Updated 1 Feb 2016

The original version of this Article contained a typographical error in the spelling of the author Chang-Hsiao Chen, which was incorrectly given as Chiang-Hsiao Chen. This has now been corrected in both the PDF and HTML versions of the Article. article's Creative Commons license, unless indicated otherwise in the credit line; if the material is not included under the Creative Commons license, users will need to obtain permission from the license holder to reproduce the material. To view a copy of this license, visit http://creativecommons.org/licenses/by/4.0/
} 